\section{Alcohol Use Disorder and Treatment in Ontario Between 2011 and 2013}

\section{A Report by the Ontario Drug Policy Research Network}

November 2015 


\section{Conflict of Interest Statement}

No study members report any affiliations or financial involvement (e.g., employment, consultancies, honoraria, stock options, expert testimony, grants or patents received or pending, or royalties) that may present a potential conflict of interest.

\section{Acknowledgments}

This study was supported by the Ontario Drug Policy Research Network (ODPRN) which is funded by a grant from the Ontario Ministry of Health and Long-Term Care (MOHLTC) Health System Research Fund. This study was also supported by the Institute for Clinical Evaluative Sciences (ICES), which is funded by an annual grant from the Ontario MOHLTC. The opinions, results and conclusions reported in this report are those of the authors and are independent from the funding sources. No endorsement by ICES or the Ontario MOHLTC is intended or should be inferred. Parts of this material are based on data and information compiled and provided by $\mathrm{CIHI}$. However, the analyses, conclusions, opinions and statements expressed herein are those of the author, and not necessarily those of $\mathrm{CIHI}$.

The study was approved by the research ethics board of Sunnybrook Health Sciences Centre, Toronto, Ontario Canada

\section{Study Team}

Sheryly Spithoff, MD, CCFP

Suzanne Turner, MD, MBS, CCFB

Diana Martins, MSc

Samantha Singh, BSc

Tara Gomes, MHSc

\section{**Update ${ }^{* *}$}

This report was updated on November 25, 2015 to revise the diagnostic codes used for define alcohol use disorders 


\section{Contents}

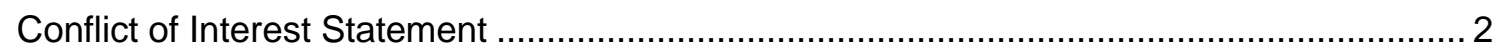

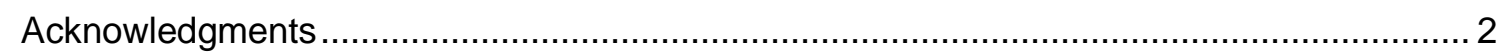

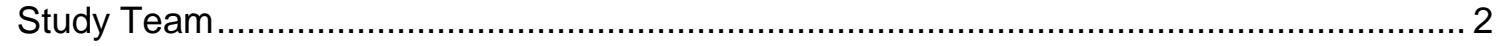

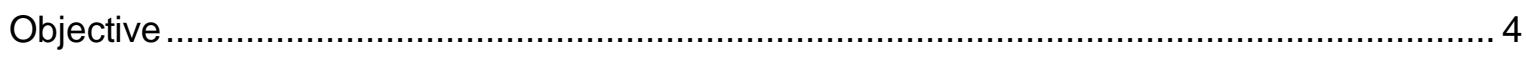

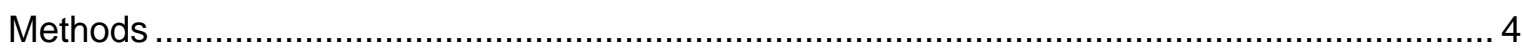

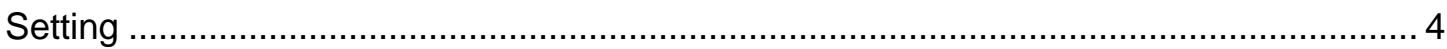

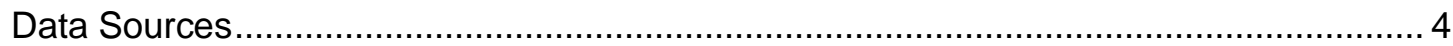

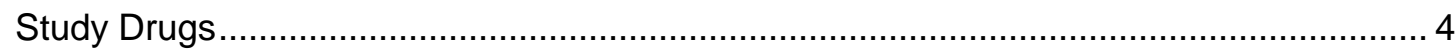

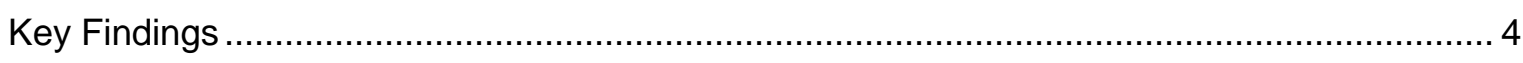

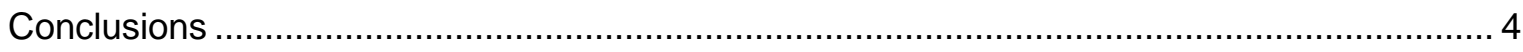

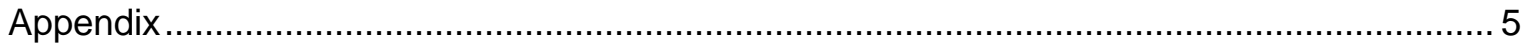

Appendix A: ICD10 codes for diagnosis of AUD ................................................. 5 


\section{Objective}

This report aims to provide preliminary data on the use of first-line medications for Alcohol Use Disorder (AUD) among public drug plan beneficiaries with a diagnosis of AUD in Ontario.

\section{Methods}

\section{Setting}

We conducted a retrospective cohort study among individuals aged 18 and older who were eligible for the Ontario Drug Benefit (ODB) Program and who had a hospital visit (inpatient or emergency department) with an AUD diagnosis (Appendix A) between April 2011 and March 2012.

\section{Data Sources}

Information regarding a diagnosis for AUD was abstracted from the Canadian Institute for Health Information Discharge Abstract Database (CIHI-DAD) and the National Ambulatory Care Reporting System (CIHI-NACRS). Public drug plan eligibility status and prescription claims for first-line AUD medications were obtained from the ODB database. The Registered Persons Database (RPDB) was used to make cohort exclusions. These datasets were linked using unique encoded identifiers and analyzed at the Institute for Clinical Evaluative Sciences (ICES). Datasets provided by ICES were linked using unique encoded identifiers and analyzed at the Institute for Clinical Evaluative Sciences (ICES).

\section{Study Drugs}

First-line AUD medications: Naltrexone and Acamprosate

\section{Key Findings}

Between April 2011 and March 2012, 15,683 individuals eligible for the ODB program with an AUD diagnosis were identified, $66.3 \%(\mathrm{~N}=10,394)$ of whom were under the age of 65 . Of those under 65 years of age, $0.36 \%(\mathrm{~N}=37)$ were dispensed a prescription for a first-line AUD medication within a year of their diagnosis. Of those 65 years of age and older, less than 6 were dispensed a prescription for a first-line AUD medication within a year of their diagnosis.

\section{Conclusions}

A small proportion of individuals with a hospital AUD diagnosis receive a first-line AUD medication within a year. Further research is needed to describe characteristics of these individuals more thoroughly. 


\section{Appendix}

\section{Appendix A: ICD10 codes for diagnosis of AUD}

\begin{tabular}{|c|c|}
\hline ICD10 code & Description \\
\hline F104 & Mental and behavioural disorders due to use of alcohol, withdrawal state with delirium \\
\hline F106 & Mental and behavioural disorders due to use of alcohol, amnesic syndrome \\
\hline F107 & $\begin{array}{l}\text { Mental and behavioural disorders due to use of alcohol, residual and late-onset psychotic } \\
\text { disorder }\end{array}$ \\
\hline F105 & Mental and behavioural disorders due to use of alcohol, psychotic disorder \\
\hline F108 & $\begin{array}{l}\text { Mental and behavioural disorders due to use of alcohol, other mental and behavioural } \\
\text { disorders }\end{array}$ \\
\hline F103 & Mental and behavioural disorders due to use of alcohol, withdrawal state \\
\hline F109 & $\begin{array}{l}\text { Mental and behavioural disorders due to use of alcohol, unspecified mental and } \\
\text { behavioural disorder }\end{array}$ \\
\hline $\mathrm{F} 102$ & Mental and behavioural disorders due to use of alcohol, dependence syndrome \\
\hline G312 & Degeneration of nervous system due to alcohol \\
\hline F101 & Mental and behavioural disorders due to use of alcohol, harmful use \\
\hline F100 & Mental and behavioural disorders due to use of alcohol, acute intoxication \\
\hline G621 & Alcoholic polyneuropathy \\
\hline 1426 & Alcoholic cardiomyopathy \\
\hline K292 & Alcoholic gastritis \\
\hline K700 & Alcoholic fatty liver \\
\hline K701 & Alcoholic hepatitis \\
\hline K703 & Alcoholic cirrhosis of liver \\
\hline K702 & Alcoholic fibrosis and sclerosis of liver \\
\hline K709 & Alcoholic liver disease, unspecified \\
\hline $\mathrm{R} 780$ & Finding of alcohol in blood \\
\hline T510 & Toxic effect of ethanol \\
\hline F104 & Mental and behavioural disorders due to use of alcohol, withdrawal state with delirium \\
\hline
\end{tabular}

